\title{
The origin of a morphologically unidentifiable human supernumerary minichromosome traced through sorting, molecular cloning, and in situ hybridisation
}

\author{
Elena Raimondi, Luca Ferretti, Bryan D Young, Vittorio Sgaramella, Luigi De Carli
}

\begin{abstract}
A supernumerary minichromosome has been detected in a severely malformed patient. Attempts at identifying the marker by conventional approaches were unsuccessful. The physical isolation of the minichromosome by fluorescence activated sorting, molecular cloning of its DNA, and in situ hybridisation experiments performed with single copy DNA probes allowed us to show that it was derived from a rearrangement involving the centromere and the proximal region of the short arm of chromosome 9.
\end{abstract}

High resolution banding is often sufficient to identify the region involved in a chromosomal rearrangement and to trace the origin of the aberration. The lower limit of resolution of this analysis is the individual chromosome band observable in prophase, which may correspond to 2 to $3 \mathrm{Mb}$. However, the morphological analysis of chromosomes frequently does not allow the reconstruction of the chromosomal changes leading to a rearrangement. Molecular hybridisation with DNA probes has been used in some cases to complement conventional cytogenetic analysis and to decide between different hypotheses. ${ }^{1-3}$

Dipartimento di Genetica e Microbiologia 'A Buzzati Traverso', Via S Epifanio 14, 27100 Pavia, Italy. E Raimondi, L Ferretti, V Sgaramella, L De Carli

IDVGA-CNR, Via Celoria 10, 20133 Milano, Italy. E Raimondi, L Ferretti

Department of Medical Oncology, ICRF, London. B D Young

Dipartimento di Biologia Cellulare, Università della Calabria, Cosenza, Italy.

V Sgaramella

Correspondence to Professor De Carli.

Received for publication 21 June 1990.

Revised version accepted for publication 30 July 1990.
A distinct class of abnormal chromosomes which may pose problems of identification is represented by the so-called 'minichromosomes' or 'microchromosomes'. These are chromosomes sized from one-third to one-fifth of the $\mathrm{G}$ group elements, usually added to a normal complement. Their pathological significance is uncertain and generally variable, since the associated symptoms may range from severe to almost normal clinical condition $\mathrm{s}^{4} \mathrm{5}$; mosaics are very frequent. In some cases the pathological traits associated with the presence of a minichromosome may serve for the selection of appropriate molecular probes localised to specific chromosomal regions. ${ }^{1}$

The stability of a minichromosome probably depends on the integrity of the centromeric and telomeric sequences. In most cases these components are expected to be functionally normal, because minichromosomes are maintained in successive cell generations.

We have observed a minichromosome (MC) in a patient with multiple malformations. Conventional chromosome analysis failed to establish the origin of the marker. For the identification of the MC several approaches have been used, based on either standard cytogenetic analyses with various banding techniques or in situ hybridisation with probes recognising centromeres or nucleolar organising regions. As none of these methods allowed us to classify the marker chromosome, we tried a direct approach based on the physical isolation of the $\mathrm{MC}$ by fluorescence activated sorting and on the construction of a genomic library.

By means of in situ hybridisation with low copy number probes derived from the MC library, we have been able to identify the $M C$ as a product of a rearrangement of chromosome 9 .

\section{Case report}

The proband, a female, was born by normal delivery at 38 weeks of gestation after a pregnancy complicated by minor problems, including allergic rhinitis, recurrent headache, and, during the last weeks, moderate hypertension. Fetal movements were felt 
at 15 weeks of gestation, but decreased fetal activity was noted after the sixth month. Birth weight was $1600 \mathrm{~g}$ ( $<3$ rd centile), she was $43 \mathrm{~cm}$ long ( $<3 \mathrm{rd}$ centile), with a head circumference of $29.8 \mathrm{~cm}(<3 \mathrm{rd}$ centile). Apgar score at one and five minutes was 10. She was admitted to a neonatal pathology department, where physical examination showed marked dysmorphic features including a narrow forehead and a large, hooked nose; the eyes were apparently normal and there was marked micrognathia. The nipples were hypoplastic. The right lower limb was hypotrophic with a reduced diameter $(1.5 \mathrm{~cm}$ at all levels); however, the length was equal to the left leg. Bilateral hammer toe was present with short halluces. The limbs were kept flexed and adducted and spontaneous movement was markedly reduced. Dorsal hyperflexion of the metacarpophalangeal and metatarsophalangeal joints associated with phalangeal flexion was present; complete extension of the elbows, hips, and knees was limited. Adduction of the hips was not possible and congenital dislocation of the right hip was present. The anal mucosa was extraverted.

Routine laboratory examinations were normal at admission and on subsequent occasions. $X$ rays showed bilateral additional ribs and confirmed the presence of congenital dislocation of the right hip.

The subsequent clinical history included severe and prolonged apnoea crises associated with tongue retroversion and the development of hypoplasia of the right facial skeleton, involving the temporal, maxillary, and frontal bones. Marked asymmetry of the thorax became evident during the third month. She survived to the third year, when she was lost to follow up.

\section{Material and methods}

CELL CULTURES AND CHROMOSOME PREPARATIONS

PHA stimulated peripheral blood lymphocytes were cultured for 72 hours in RPMI 1640 medium supplemented with 15\% FCS. For Epstein-Barr virus (EBV) immortalisation, lymphocytes were separated on a Ficoll-Hypaque gradient and infected with EBV produced by B95-8 marmoset cells. ${ }^{6}$ For $R$ banding, $\mathrm{BrdU}(30 \mu \mathrm{g} / \mathrm{ml})$ was added during the last seven hours in culture before harvesting. For high resolution banding the cells were synchronised with MTX for 16 hours.

Chromosome preparations were performed after a two hour treatment with colcemid $(0.03 \mu \mathrm{g} / \mathrm{ml})$ according to the standard procedure, based on hypotonic swelling in $\mathrm{KCl} 0.075 \mathrm{~mol} / \mathrm{l}$ and fixation in methanol:acetic acid (3:1).

\section{STAINING AND BANDING}

Chromosomes were counted on Giemsa stained metaphases. The karyotypes of the patient and her parents were analysed on QFQ banded mitoses from peripheral blood cultures. GTG, RBG ${ }^{78}$ dystamicin A/DAPI, ${ }^{9}$ and NOR banding ${ }^{10}$ was performed on the EBV transformed lymphocytes of the patient.

\section{DNA PROBES}

E5 (courtesy of G N Ranzani) corresponds to the 3' terminal region of the $28 \mathrm{~S}$ rRNA gene and a portion of the adjacent, non-transcribed spacer; it is a $7 \mathbf{~ k b}$ BamHI fragment cloned in pUC8.

The MC probes were isolated from a library of $E c o$ I fragments derived from the sorted MC DNA, cloned into $\lambda g t W E S / B^{\prime}{ }^{11} 12$ Single copy DNA probes were selected as plaques non-hybridising to labelled human DNA after two rounds of hybridisation to plaque lifts of the MC library according to standard protocols. ${ }^{13}$ Each of the probes selected identified a single fragment when hybridised to total human DNA restricted with $E c o$ RI. The average size of the inserts was $6.5 \mathrm{~kb} .{ }^{12}$

PROBE LABELLING AND IN SITU HYBRIDISATION

The probes were labelled by nick translation with a commercial kit (Amersham) using three tritiated nucleotides: ${ }^{3} \mathrm{H}-\mathrm{dATP},{ }^{3} \mathrm{H}-\mathrm{dCTP}$, and ${ }^{3} \mathrm{H}-\mathrm{dTTP}$. The specific activity ranged from $4 \times 10^{7}$ to $10^{8}$ $\mathrm{cpm} / \mu \mathrm{g}$. The labelled probes were separated from unincorporated precursors on a Sephadex G-50 column, then precipitated with two volumes of ethanol, and resuspended in hybridisation buffer $^{1}$ at concentrations ranging from 50 to $500 \mathrm{ng} / \mathrm{ml}$. The probes were denatured for 10 minutes at $70^{\circ} \mathrm{C}$ and quick chilled in ice.

In situ hybridisation was performed essentially as previously described. ${ }^{14}$ Briefly, slides were treated with RNase (type III, Sigma) at $37^{\circ} \mathrm{C}$ for one hour and dehydrated through an ethanol series before denaturation in $70 \%$ formamide $/ 2 \times$ SSC. After denaturation the slides were placed into cold $2 \times$ SSC and dehydrated through an ethanol series at $4^{\circ} \mathrm{C}$. Solutions with different concentrations of the probes were placed onto the slides under a coverslip and hybridised overnight at $42^{\circ} \mathrm{C}$. The slides were then washed four times in $50 \%$ formamide $/ 2 \times \mathrm{SSC}$ at $39^{\circ} \mathrm{C}$ for 10 minutes, three times in $2 \times \mathrm{SSC}$ at $39^{\circ} \mathrm{C}$ for 10 minutes, three times in $2 \times S S C$ at room temperature for 10 minutes, and twice in $0.1 \times S S C$ at room temperature for one hour. Parallel experiments with all the probes derived from the MC library were performed under conditions of higher stringency by increasing the hybridisation temperature to $47^{\circ} \mathrm{C}$ and raising the formamide of the washes to $52 \%$ at $39^{\circ} \mathrm{C}$.

For autoradiography the slides were dipped in Kodak NTB-2 emulsion $1 / 1$ diluted in $2 \%$ glycerol, exposed for 7 to 30 days at $4^{\circ} \mathrm{C}$, and finally developed in Kodak D-19 and fixed in Kodak Unifix. The slides 
were Giemsa stained after autoradiography and photographed for the analysis of the distribution of the silver stains. They were then RBG banded and photographed again to identify the labelled chromosomes.

\section{Results}

A preliminary cytogenetic analysis was performed on $Q$ banded peripheral blood lymphocytes of the patient as well as her parents. While the latter were karyotypically normal, a mosaic $46, \mathrm{XX} / 47, \mathrm{XX},+$ mar/ $47, \mathrm{XX},+9$ was detected in the patient. The chromosome counts performed on the MC lymphoblastoid cell line derived from peripheral blood lymphocytes of the patient and the proportion of different cell types at different times in culture are shown in the table. Little variation in the frequency of cells with the $M C$ around a mean value of $66 \%$ was observed over more than 30 passages, whereas a marked fluctuation was noticed in the frequency of cells with the trisomy 9 , which represented a minority of the cell population.

The size of the MC was estimated to be about $40 \%$ of that of $\mathrm{G}$ group chromosomes (corresponding to 20 to $25 \mathrm{Mb}$ ). $\mathrm{R}$ banding also indicated that about two thirds of the MC consisted of euchromatic material. Other differential staining showed that the $M C$ was $C$ band positive and DA-DAPI and NOR negative. In situ hybridisation with a probe corresponding to the 3' terminal region of the $28 \mathrm{~S}$ ribosomal RNA gene (E5) ruled out the possibility that the MC originated from a simple rearrangement involving the short arms of the acrocentric chromosomes: an intense labelling was present on all the acrocentric chromosomes, while no autoradiographic grains could be visualised on the MC (data not shown).

Because of the failure of conventional cytogenetic methods to identify the $\mathrm{MC}$, we proceeded to chromosome sorting, DNA cloning, and in situ hybridisation. The sorting experiments have already been described by Ferretti et al. ${ }^{11}$ Clones selected from the MC library as harbouring low copy number DNA sequences (see Materials and methods) were hybridised to metaphases containing the $\mathrm{MC}$ in order to verify their specificity for the marker. The total number of autoradiographic grains and the number of grains hybridising to the $M C$ were scored on at least 50 metaphases for each of the probes tested. A $\chi^{2}$ test was performed in order to evaluate the significance of the difference between the number of grains observed on the MC and that expected on the basis of its relative size, assuming a random distribution of grains on all the chromosomes. Only those clones showing a significant deviation from the expected value $(p<0.001)$ were considered specific for the MC. Four out of 15 probes tested, namely MC29 (D9S36), MC59, MC65 (D9S38), and MC114 (D9S40), were shown to be positive. ${ }^{15}$ The low proportion of specific clones observed indicates that a considerable quantity of non-specific DNA sequences was contaminating the MC library: a likely explanation for this is that the MC peak, as visible in the FACS profile, was overlapping a region containing debris originating from chromosomal breakage. ${ }^{11}$ Three of the positive clones, MC29, MC65, and MC114, were in situ hybridised to metaphases of normal and MC cells in order to identify the chromosomal region from which the marker originated. Given the relatively large size
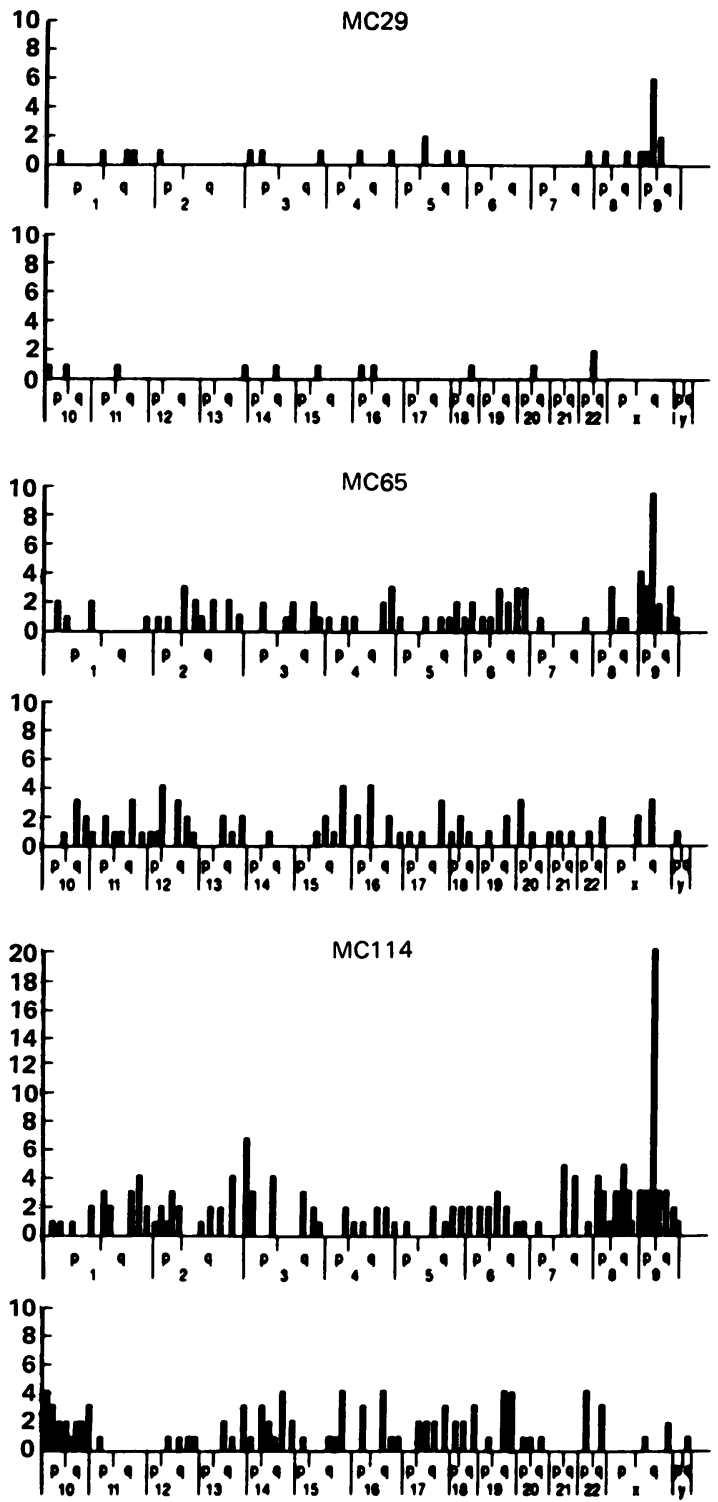

Figure 1 Distribution of silver grains on normal lymphocytes hybridised in situ with probes MC29, MC65, and MC114. 
Chromosome counts on peripheral blood lymphocytes of the patient and on a lymphoblastoid cell line obtained after EBV transformation.

\begin{tabular}{|c|c|c|c|c|}
\hline $\begin{array}{l}\text { Passage } \\
\text { number }\end{array}$ & $\begin{array}{c}\% \text { of cells } \\
46, \mathrm{XX}\end{array}$ & $\begin{array}{c}\% \text { of cells } \\
47, \mathrm{XX},+\mathrm{mar}\end{array}$ & $\begin{array}{l}\% \text { of cells } \\
47, X X,+9\end{array}$ & $\begin{array}{l}\text { No of mitoses } \\
\text { analysed }\end{array}$ \\
\hline $\begin{array}{l}\text { Peripheral blood } \\
\text { lymphocytes } \\
\text { Lymphoblastoid cells }\end{array}$ & 26 & 70 & 4 & 50 \\
\hline 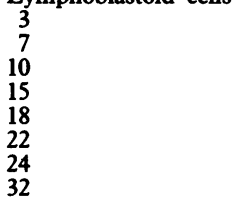 & $\begin{array}{l}32 \\
28 \\
24 \\
20 \\
20 \\
22 \\
20 \\
34\end{array}$ & $\begin{array}{l}68 \\
64 \\
52 \\
73 \\
56 \\
68 \\
78 \\
62\end{array}$ & $\begin{array}{r}0 \\
8 \\
24 \\
7 \\
24 \\
10 \\
2 \\
4\end{array}$ & $\begin{array}{l}20 \\
50 \\
50 \\
44 \\
50 \\
50 \\
50 \\
50\end{array}$ \\
\hline
\end{tabular}

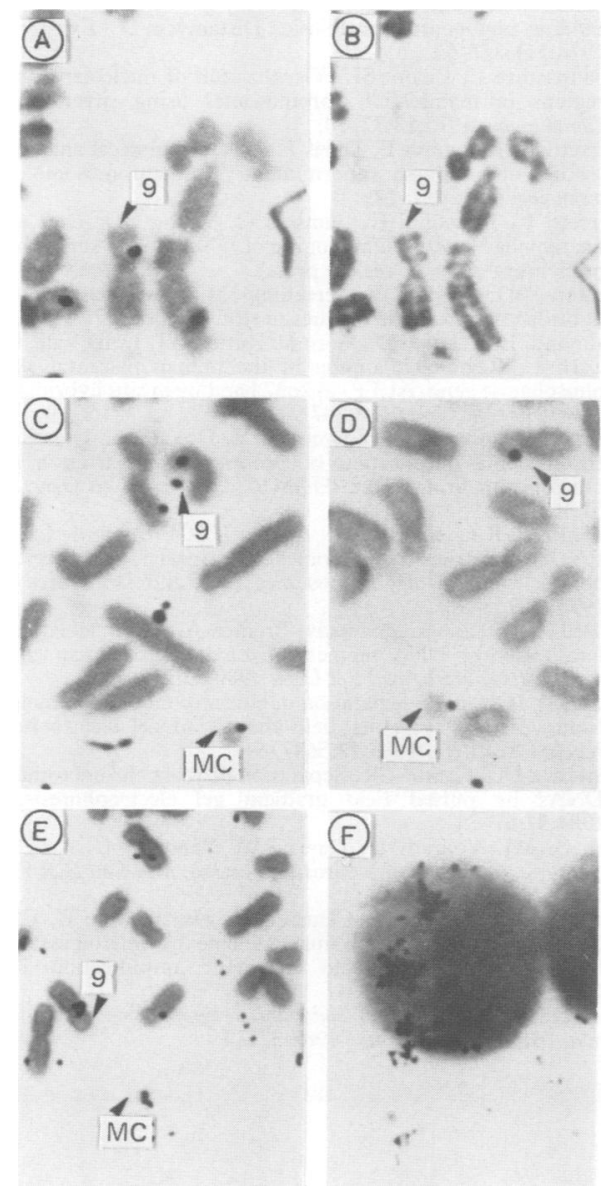

Figure 2 In situ hybridisation with $M C$ specific DNA probes. $(A, B)$ Partial metaphase of normal lymphocytes showing the specific label in 9p13: (A) Giemsa staining. (B) RBG banding. $(C, D, E)$ Partial metaphases of $M C$ cells showing both the specific signal on the MC and the site of hybridisation on normal chromosome 9. (F) Interphase nucleus of an MC cell clearly showing the partial trisomy 9. of the inserts (MC29 8.1 kb, MC65 more than $10 \mathrm{~kb}$, and $\mathrm{MC1} 148.5 \mathrm{~kb}$ ), stringent conditions were used to perform the in situ hybridisation (see Materials and methods), in order to minimise the contribution of repetitive DNA to the autoradiographic signal. The grain distributions are shown in fig 1 . A prominent peak is evident on the same region of chromosome 9 with all of the probes. This finding is consistent with the data obtained from the analysis of a human-rodent cell hybrid panel (data not shown). By in situ hybridisation the three DNA fragments could be mapped to 9p13-cen. Fig 2 shows partial metaphases of normal lymphocytes $(A, B)$ and of $M C$ cells $(C, D, E)$ hybridised with the MC specific probes. Hybridisation signals on both the MC and on the 9p13-cen region are evident. An interphase nucleus of an MC cell is shown in fig $2 \mathrm{~F}$, which gives supportive evidence in favour of the partial trisomy 9 .

\section{Discussion}

A combined cytological and molecular approach has been successfully used to establish the origin of an unidentified, small, extra chromosome. The sequential steps included the fluorescence activated sorting of the marker chromosome, the production of a chromosome specific DNA library, the selection of clones corresponding to low copy number sequences, and in situ hybridisation with the isolated DNA probes.

The method is certainly laborious and time consuming, but, under circumstances such as those encountered in the case reported, it is necessary to arrive at the identification of the chromosome. Callen et $a l^{16}$ have recently described a rapid and simple in situ method for the identification of supernumerary markers using probes to chromosome specific pericentric repeats. We did try a similar approach using a 9 specific repetitive DNA probe (QP23, courtesy of $M$ Jeanpierre) in order to characterise the $M C$ better before sorting. A much weaker signal was detected on the MC than on the normal chromosome 9 (data not shown). To account for these results, the occurrence 
of a deletion in the pericentromeric region of the MC can be postulated. Therefore, the approach suggested by Callen $e t a l^{16}$ was unsuitable for the identification of our MC.

Alternatives to sorting for the isolation of the MC, such as the production of monochromosomic interspecific hybrids ${ }^{17}$ or pulsed field gel electrophoresis (PFGE), ${ }^{18}{ }^{19}$ were not considered since the production and maintenance of monochromosomic cell hybrids has an extremely low probability in the absence of a selective system, while PFGE has not yet been applied for the isolation of fragments larger than $12 \mathrm{Mb}^{20}$ Recent developments in the microdissection of chromosomes ${ }^{21}$ make it a very promising approach for isolating and cloning sequences directly from the $M C$, thus avoiding the cloning of non-specific DNA derived from chromosomal debris sorted along with the MC. ${ }^{11}$

With the aid of the DNA library derived from the $M C$ we have been able to restrict the origin of the marker to the region 9p13-cen where all the probes tested were localised.

To establish a possible correlation between the clinical phenotype of the patient and the presence of the small supernumerary chromosome identified as a number 9 derivative, attention should be given to the presence of a complete mosaic trisomy 9 . Though present in a low proportion of cells, this may be sufficient to account for the observed pathological symptoms, such as severe micrognathia, joint luxations, additional ribs, and severe reduction in size of one leg, that are traits associated with mosaic trisomy. ${ }^{22}$

We are grateful to Professor G Camerino and Dr F De Benedetti for helpful suggestions and discussion and to Dr P Mignatti for critically reading the manuscript. The authors wish to thank $\operatorname{Dr} L$ A Magni for referring the patient along with the clinical history. This work was supported by grants from CNR, PF Biotechnologie, and PF Ingegneria Genetica.

1 Mattei MG, Philip N, Passarge E, Moisan JP, Mandel JL, Mattei JF. DNA probe localization at 18 p113 band by in situ hybridization and identification of a small supernumerary chromosome. Hum Genet 1985;69:268-71.
2 Lichter P, Cremer T, Chang Tang C, Watkins PC, Manuelidis L, Ward DC. Rapid detection of human chromosome 21 aberrations by in situ hybridization. Proc Natl Acad Sci USA 1988;85: $9664-8$.

3 Raimondi E, Vagnarelli P, Bensi M, De Carli L. Characterization of an $\mathrm{X} ; \mathrm{X}$ translocation by cytological analysis and in situ hybridisation. Cytogenet Cell Genet 1989;50:123-4.

4 Mattei JF, Philip N, Mattei MG, Giraud F. Les petits chromosomes surnumeraires. 7 Genet Hum 1985;33:389-96.

5 Stamberg J, Thomas GH. Unusual supernumerary chromosomes: types encountered in a referred population, a high incidence of associated maternal chromosome abnormalities. Hum Genet 1986;72:140-4.

6 Ragona G, Frezza D, Fruscalzo A, et al. Studies on host-virus genome relationship in Epstein-Barr virus immortalized lymphoblastoid cell lines. Cell Biol Int Rep 1986;10:315-21.

7 Perry P, Wolff S. New Giemsa method for the differential staining of sister chromatids. Nature 1974;251:156-8.

8 Camargo M, Cervenka J. Patterns of DNA replication of human chromosomes. II. Replication map and replication model. $A m \boldsymbol{F}$ Hum Genet 1982;34:757-80.

9 Schweizer D, Ambros P, Andrle M. Modification of DAPI banding on human chromosomes by prestaining with a DNA binding oligopeptide antibiotic, Distamycin A. Exp Cell Res 1978;111:327-32.

10 Goodpasture C, Bloom SE. Visualization of nucleolar organizer regions in mammalian chromosomes using silver staining. Chromosoma 1975;53:37-50.

11 Ferretti L, Raimondi E, Davis L, et al. Cytological analysis and sorting of a human supernumerary minichromosome. Cytotechnology 1987;1:7-12.

12 Ferretti L, Raimondi E, Gamberi C, Young BD, De Carli L, Sgaramella V. Molecular cloning of DNA from a sorted human minichromosome. Gene (in press).

13 Benton WD, Davis RW. Screening $\lambda$ gt recombinant clones by hybridization to single plaques in situ. Science 1977;196:180-2.

14 Raimondi E, Talarico D, Moro L, Rutter WJ, Della Valle G, De Carli L. Regional mapping of the human placental alkaline phosphatase gene (ALPP) to 2q37 band by in situ hybridization. Cytogenet Cell Genet 1988;47:98-9.

15 Raimondi E, Ferretti L, Sgaramella V, De Carli L. Isolation and chromosomal localization of probes derived from a sorted human minichromosome. HGM10. Cytogenet Cell Genet 1989; 51:1063.

16 Callen DF, Ringenbergs ML, Fowler JCS, Freemantle CJ, Haan EA. Small marker chromosomes in man: origin from pericentric heterochromatin of chromosomes 1, 9, and 16. J Med Genet 1990;27:155-9.

17 Gusella JF, Keys C, Varsanyi-Breiner A, et al. Isolation and localization of DNA segments from specific human chromosomes. Proc Natl Acad Sci USA 1980;77:2829-33.

18 Carle GF, Olson M. Separation of chromosomal DNA molecules from yeast by ortogonal-field-alternation gel electrophoresis. Nucleic Acids Res 1984;12:5647-64.

19 Schwartz DC, Cantor CR. Separation of yeast chromosome sized DNAs by pulsed field gradient gel electrophoresis. Cell 1984;37:67-75.

20 Orbach MJ, Vollrath D, Davis RW, Yanofsky C. An electrophoretic karyotype of Neurospora crassa. Mol Cell Biol 1988;8: 1469-73.

21 Ludecke HJ, Senger G, Claussen U, Horsthemke B. Cloning defined regions of the human genome by microdissection of banded chromosomes and enzymatic amplification. Nature 1989;338:348-50.

22 Schinzel A. Catalogue of unbalanced chromosome aberrations in man. Berlin: de Grutyer, 1984:371-4. 